\title{
Development the Health Learning Center System for Provincial Hospitals in Thailand
}

Ratchaneewan Tangpakdee ${ }^{1 *}$, Onjaree Natakuatoong² and Chaiyong Brahmawong ${ }^{3}$

${ }^{1}$ Department of Educational Technology and Communications, Faculty of Education, Mahasarakham University, Thailand ${ }^{2}$ Department of Educational Technology and Communications, Faculty of Education, Chulalongkorn University, Thailand

${ }^{3}$ Distance Education Department, Bangkokthonbhuri University, Thailand

\begin{abstract}
The purpose of this research was to develop a Health Learning Center (HLC) System for provincial hospitals in Thailand. The methodology of this study using R\&D processes, consisted of four steps: (1) studying the factors relating to the states and problems of existing HLC system, (2) developing the HLC system prototype from obtained information and validating the prototype, (3) implementing the HLC system prototype in three provincial hospitals, and (4) certifying the HLC system and proposing the final HLC system. Qualitative instruments included a reflection log, a semi-structure interview guide and an observation guide.

The research findings revealed that the HLC system for provincial hospitals in Thailand comprised four main systems as follow: (1) HLC Establishing System, (2) HLC Planning System, (3) HLC Operating System: including six sub-systems: (3.1) knowledge corner development sub-system, (3.2) health learning activity sub-system, (3.3) health education and behaviors network supporting sub-system, (3.4) production and procurement of educational media subsystem, (3.5) health knowledge database sub-system and (3.6) health information management sub-system, and (4) HLC Evaluation System.

This HLC System was developed as management tools for staff at all levels in order to develop on health learning center for their clients and the general public at risk of various diseases through individual and group active learning. Replication of this HLC system can be modified to be implemented in provincial hospitals. In addition, this system was a model of HLC System of hospitals in the district level throughout Thailand as well.
\end{abstract}

Keywords: Health learning center; Health promotion; Learning center system

\section{Introduction}

According to the World Health Organization, health promotion is the process of enabling people to increase control over, and to improve, their health [1]. Health promotion and health education is an increasingly diverse and ever-changing field. It is a process comprising of consciously constructed opportunities for learning and communication designed to improve health information, health literacy, health knowledge, and developing life skills which are conducive to the promotion of an individual and community's health through health promotion and health education activities. In Thailand, many different stakeholders are involved in efforts to improve health [2]. Some hospitals recognize their work as health promotion or health education and are guided by a range of existing policy initiatives and frameworks [3].

In 2003, Health Education Division, Ministry of Public Health, developed the Technology and the Health Communication Systems (THCS) for hospitals throughout the country to support the health promotion and health education programs. This system comprises of all of the management procedures used to improve media planning and utilization, health communication, and project evaluation. After the implementation of THCS, the demands for health education and health learning center (HLC) in hospitals has been increasing in recent years. The HLC is one of the essential components of health promotion and health education in hospitals. It is an area activity that allows clients to manipulate materials, explore best practices, discover skills, build, create and express themselves through health medium. It contains systematic instruction and learning activities, learning corners, and various learning materials and equipment [2]. Conformingly, Karam et al. [4] found that responsible cost benefit analysis will give healthcare providers a strong stance to justify programs. Using a study of pediatric patients with the same diagnosis and initial treatment, they evaluate the cost benefit of a patient-education intervention. Two groups of patients, one with the patient education and the other without, were evaluated as to their utilization of healthcare services resulting from noncompliant behavior. There is less of an incidence of complications with the formalized patient-education program. In deriving a benefit to cost ratio of over seven to one, the effectiveness of the program was demonstrated. People assuming responsibility for their own health is a benefit to the society at large.

In any organization, there are certain functional areas that provide crucial internal support and service to the rest of the organization [5]. In provincial hospitals, the breakdown of any one or combination of health promotion and health education functions can have wideranging impacts on the ability of the hospital to deliver better learning activities. As people tend to look at the learning functions as "central service," or "support" activities, the staffs providing learning activities are seldom informed of the importance of their work. Conversely, staffs in all functions frequently fail to see that any of their work has a direct impact on the ability of the hospital to deliver timely, accurate,

*Corresponding author: Ratchaneewan Tangpakdee, Department of Educational Technology and Communications, Faculty of Education, Mahasarakham University, Thailand, Tel: +668-159-22270; E-mail: ratchaneewanmsu@hotmail.com

Received April 19, 2013; Accepted July 17, 2013; Published July 24, 2013

Citation: Tangpakdee R, Natakuatoong O, Brahmawong C (2013) Development the Health Learning Center System for Provincial Hospitals in Thailand. J Health Med Informat 4: 127. doi:10.4172/2157-7420.1000127

Copyright: (C) 2013 Tangpakdee R, et al. This is an open-access article distributed under the terms of the Creative Commons Attribution License, which permits unrestricted use, distribution, and reproduction in any medium, provided the original author and source are credited. 
and valuable learning services. Since the Health Learning Center's mission is to promote health learning of children, families, schools, and communities by providing resources and activities, in order to manage HLC functionally, the process for every function of the hospital should be designed systematically [2].

This HLC was designed and developed under the concept of educational technology and universal design. Educational technology is the study and ethical of facilitating learning and improving performance by creating, using, and, managing appropriate technological processes and resources. The universal design or the creation of resources that are broadly useful to as many people as possible helps to ensure that resources are created with the diverse needs of potential users in mind [1]. Moreover, the process approach was used so as to create a management strategy for HLC [6]. It is believed that when managers use a process approach, it means that they manage the processes that make up their organization, the interaction between these processes, and the inputs and outputs that glue these processes together. A system exists whenever several processes are interconnected using such inputoutput relationships [7].

Therefore, the purposes of this study were to examine the components and steps particular to HLC system and to identify details that contribute to health learning center effectiveness and positive outcomes for hospital staff in every function a health learning center of provincial hospital.

\section{Objective}

To develop a System of Health Learning Center in provincial hospitals in Thailand.

\section{Research Methods}

\section{Research methodology}

This study was a research and development study during the time period of 2008-2010 using qualitative methodology, consisted of four steps:

Step 1: Studying the factors relating to the states and problems of existing HLC system: The researcher studied from documents and wide range of related research about health learning center. Then, the researcher proceeded with an in-depth field study through structured interviews to collect states and problems in the operations of the health learning centers in the following four provincial hospitals: (1) Buddhachinaraj hospital, Phitsanulok; (2) Supprasitprasong hospital, Ubonratchathanee; (3) Saraburi hospital, Saraburi; and (4) Uthaithani hospital, Uthaithani.

Step 2: Developing the HLC system prototype: The researcher used the data collected in the step 1 to develop a prototype of health learning center system for provincial hospitals, and verified the prototype by using the focus-group technique. Participants in the focus group consisted of nine specialists who were highly experienced in communication technology in the field of health education and behaviors. The experts' comments and suggestions were used to improve the prototype system.

Step 3: Implementing the HLC system prototype: The improved prototype system was implemented in three selected provincial hospitals in north-eastern, southern, and central regions of Thailand comprising (1) Mahasarakham Hospital, Mahasarakham (2) Trang Hospital, Trang and (3) Uthaithani Hospital, Uthaithani. During the experimental period of one year, the researcher followed-up and monitored the use of the trial-version model in the hospitals by using participating observation technique three times for each hospital in 6 months. Furthermore, the model was also evaluated using in-depth interview by the staff of the health learning centers in the participating hospitals. All the data collected through the above processes were then concluded and used to further improve the health learning center system prototype.

Step 4: Certifying the HLC system and proposing the final HLC system: The improved health learning center system model from step 3 was then brought up to the certification step by using the focusgroup approach with 19 specialists who were representatives from the health learning center development working groups from provincial hospitals in the regions. Final improvement had been incorporated into the system based on the comments, suggestions and other information gathered from the experts during the certification process before proposing the final health learning center system for provincial hospitals throughout Thailand.

\section{Sample}

The sample in this study are four provincial hospitals with 10 staff members involved in the field-study stage and three provincial hospitals with 200 staff members participated in the HLCS implementation and follow-up stages. Selection of participants for the qualitative data was purposive, based on the informants' extensive involvement and knowledge of HLC. 28 specialists were also included in the two focus group meetings, nine specialists for system confirmation prior to system implementation and 19 specialists for HLCS validation after system implementation.

\section{Results}

\section{The result of development the health learning center system for provincial hospital in Thailand}

By result of the study, researcher has developed Health Learning Center System for provincial hospital in Thailand. This system facilitates HLC establishment and HLC development for hospitals throughout the country. It assists hospital staffs to plan, operate and evaluate HLC performance systematically and be consistent with The Health Promotion Development guideline of Hospital Accreditation (H.A.), Health Promoting Hospital Standard (H.P.H.) and Health Education Accreditation (H.Ed.) in Thailand. HLC in Hospitals will be useful sources to provide health education to public with the purposes to promote public health appropriately and reduce the morbidity of population sustainably.

The HLC system composes of four main systems as follows: The HLC system composes of four main systems as follows:

\section{HLC establishing system}

It facilitates the establishment of HLC. This system includes five steps: 1.0 determines and assesses needs and scope, 2.0 prepare requirements and resources, 3.0 establish committees (administrative board and/or staff), 4.0 develop a project plan, and 5.0 Execute approved projects.

\section{HLC planning system}

It used to create detailed strategic plan steps. This system includes six steps: 1.0 develop a HLC strategic plan, 2.0 establish priority for sub-system adoption, 3.0 document sub-system project and action plan for administrative board approval, 4.0 set up HLC committees meeting (advisory board and staff) to clarify and communicate responsibilities 
for project action plan, 5.0 implement sub-systems action plan, and 6.0 monitor the implementation of plans and if require making proper amendments.

\section{HLC Operating System}

It is the actual operation of all learning areas and activities. It includes six sub systems

\section{Knowledge corner development sub-system}

It is developed to help the staff of the hospital to establish the knowledge corner systematically so that its content corresponds to the demand and the problems of the organization and its clients. This sub-system includes ten steps; 1.0 study the demand for and the problem of developing the knowledge corner, 2.0 specify the area to set up the knowledge corner, 3.0 select and analyze the target group, 4.0 analyze the content to be provided in the knowledge corner, 5.0 produce and procure equipment for the knowledge corner,6.0 propose rules and regulations for the use of the knowledge corner, 7.0 set up the knowledge corner, 8.0 provide the knowledge corner service, 9.0 collect the information on the knowledge corner service, 10.0 evaluate the development of the knowledge corner.

\section{Health learning activity sub-system}

It is developed to help the staff of the hospital plan and conduct the activities systematically. These activities will be adaptable to the situations, and suitable for the environment and the target group. This sub-system includes eleven steps; 1.0 analyze the situation regarding health problems in the activity area, 2.0 analyze and define the target group, 3.0 specify the objective of the activity, 4.0 analyze and specify the content of the activity, 5.0 select the media and equipment to be used in the activity, 6.0 analyze the appropriateness of the environment for arranging the activity, 7.0 Select the method of arranging the activity, 8.0 develop the activity-arrangement plan or guideline, 9.0 conduct the activity, 10.0 collect the information of the activity arrangement, and 11.0 evaluate the activity arrangement.

\section{Health education and behaviors network supporting sub- system}

It is developed to help the staff of the hospital to create the plan for supporting health education and health behavior learning network. Whence, the network will be able to provide health education and health behavior learning systematically. Also, the health education and health behavior learning will conform with the situations, its problem and demand, and appropriate for the target group that is the members of the network. This sub-system has ten steps; 1.0 survey and create the directory of health education and health behavior learning network of the hospital, 2.0 study the problem of and the demand for health education and health behavior learning of the network, 3.0 indicate the support the network requires for the provision of health education and health learning behavior, 4.0 analyze and specify the target group which requires the support for the provision of health education and health behavior learning, 5.0 analyze and select the content of health education and health behavior learning suited to the network, 6.0 select the method of supporting the network's health education and health behavior learning, 7.0 create the operational plan to support the network's health education and health behavior learning, 8.0 support the network's health education and health behavior learning, 9.0 collect the information of supporting the network's health education and health behavior learning, 10.0 evaluate the support of health education and health behavior learning of the network.

\section{Production and procurement of educational media sub- system}

It developed to help the hospital staff to produce and procure the educational media systematically so that they are in line with the content, knowledge transfer method and the target group. This subsystem has eleven steps; 1.0 study the demand for the educational media of the staff of the knowledge service in the hospital, 62.0 analyze and identify the target group, 3.0 specify the objective of the production and the procurement of the educational media, 4.0 analyze and select the content of the educational media, 5.0 select the educational media to be produced or procured, 6.0 survey the educational media available of the hospital, 7.0 produce or procure the equipments, 8.0 test the efficiency of the educational media, 9.0 provide the educational media service, 10.0 collect the information of the production and the procurement of the educational media, and 11.0 evaluate the procurement and procurement of the educational media.

\section{Health knowledge database sub-system}

It developed to help the hospital staff to collect the information on the knowledge of health education and health behaviors systematically via the website of health learning center network developed by the Health Education Division or via the health education and health behaviors database developed by the hospital. This sub-system has nine steps; 1.0 study the demand for the health education and health behavior knowledge, 2.0 gather the health education and health behavior knowledge, 3.0 manage the health education and health behavior knowledge, 4.0 select the data storage for the health education and health behavior knowledge, 5.0 set up the health education and health behavior knowledge in the database, 6.0 try out the health education and health behavior knowledge database, 7.0 use the health education and health behavior database, 8.0 maintain the health education and health behavior database, 9.0 evaluate the health education and health behavior database.

\section{Health information management sub-system}

It developed to help the staff of the hospital to manage health information systematically and thoroughly for easy access. This subsystem has eight steps; 1.0 analyze the demand for the health education and health behavior information management system, 2.0 gather the data for developing the health education and health behavior information management system, 3.0 design the health education and health behavior information management system, 4.0 develop the health education and health behavior information management system, 5.0 try out the health education and health behavior information management system, 6.0 use the health education and health behavior information management system, 7.0 maintain the health education and health behavior information management system, and 8.0 evaluate the health education and health behavior information management system.

\section{HLC evaluation system}

It facilitates the HLC staff in the process of formative and summative evaluation in order to improve all three systems and sub-systems. This system includes seven steps: 1.0 identify target of the evaluation and evaluators, 2.0 specify objectives of the evaluation, 3.0 select criteria and indicator for evaluation, 4.0 determine data collection methods and develop instruments for evaluation, 5.0 set up a meeting to communicate methods and criteria to all stakeholders, 6.0 implement the evaluation and gather data as planned, and 7.0 report findings and give recommendations for improvement. 
Citation: Tangpakdee R, Natakuatoong O, Brahmawong C (2013) Development the Health Learning Center System for Provincial Hospitals in Thailand. J Health Med Informat 4: 127. doi:10.4172/2157-7420.1000127

Page 4 of 5

According to the presentation about components of each learning center system mentioned above, each main system has different procedures. Moreover, the implementation of internal systems, external systems and subsystems are correlated with each other as shown in Figure 1 .

\section{The result of HLC system implementation in provincial hospital}

After HLC system was implemented in three provincial hospitals, namely Mahasarakham hospital, Trang hospital and Uthaithani hospital. Researcher found that the HLC system was successful and applicable to all provincial hospitals and there are 8 key factors supporting the achievement of HLC development in provincial hospital as following;

(1) Hospital executives must recognize the importance and impact of giving health knowledge information to public. Ready to be consultants in the implementation process and fully provide support in terms of policy and budget for HLC establishment in the hospital.

(2) Staffs in the agencies responsible for health education in hospitals need to be tough, have good coordination skills with the ability to manage operation and facilitate staffs from other agencies who is working at health learning center as a team.

(3) Hospital staffs must have positive attitude toward working as instructors and be able to integrate public health knowledge instructor job into daily work.
(4) Implementation of the Health Learning Center will be sustainable by allowing people to participate in who various parts.

(5) Encourage staff to work and motivate other agencies to follow by arranging contest and giving award to agencies which accomplish excellent HLC.

(6) Regularly providing learning activities in order to improve knowledge, develop techniques and skills, and optimizing procedure in HLC are absolutely necessary in development of learning centers to improve efficiency and quality constantly.

(7) Forming HLC network both between departments within the hospital and between hospital and external organizations will carry knowledge and good practice sharing. Moreover, they will be good partnerships to support health promotion activities to each other.

(8) Systematical and appropriate performance evaluation can support the development of hospital in proper direction.

\section{Discussion}

On the basis of a literature review and a field study on existing interventions in HLC in selected provincial hospitals, no other studies have either implemented or developed the systematic intervention in the same manner as this study. Thus, this study is unique in its definition, operation, and conceptualization of health learning. Some of these unique features are the breadth of hospitals engaged in the HLC development and the authenticity of the collected data. The system focuses on the entire organization rather than individual department or ward activity.

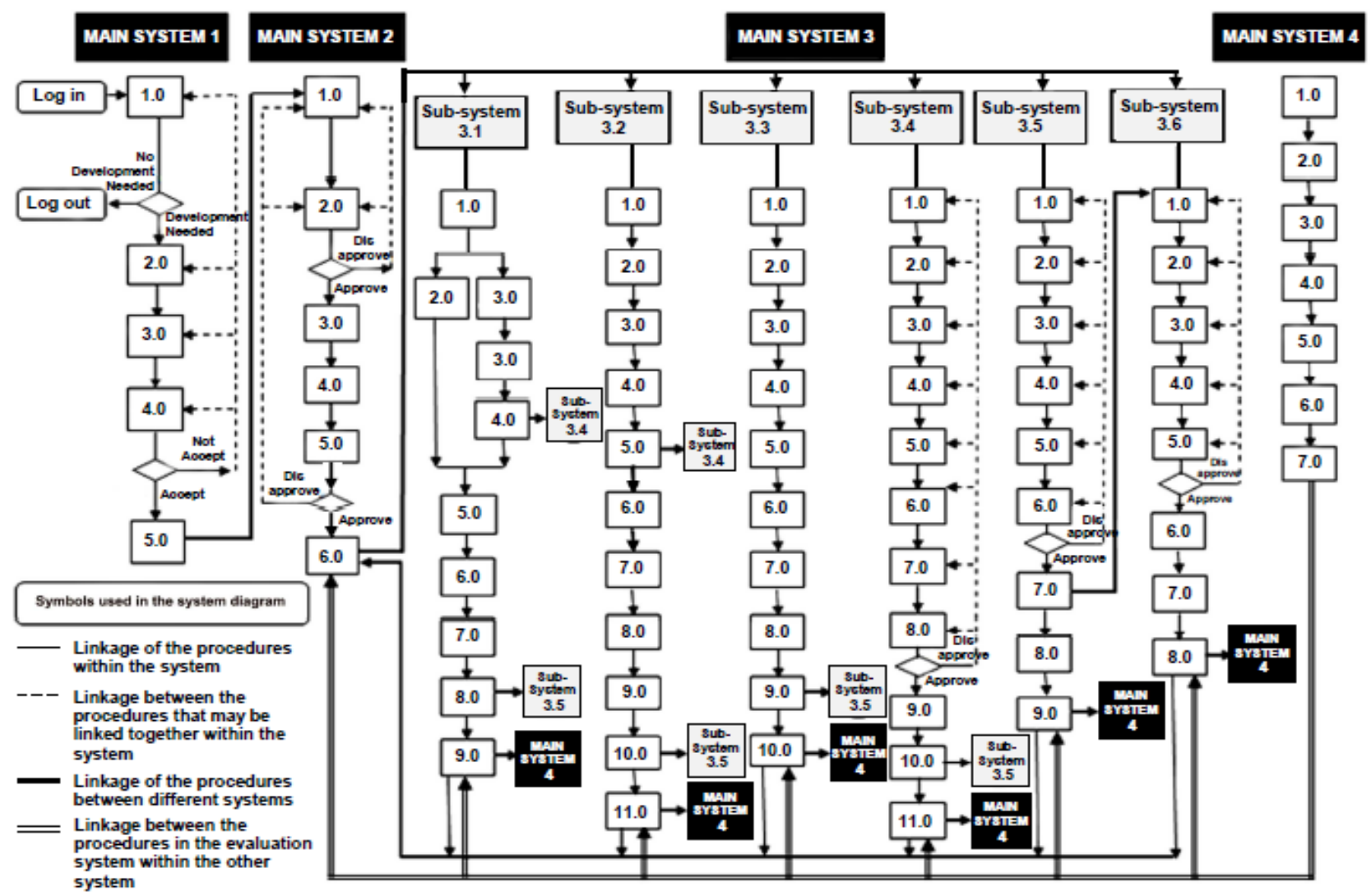

Figure 1: Inter-relationship in operation process of the Health Learning Center System in Provincial hospitals in Thailand. 
Citation: Tangpakdee R, Natakuatoong O, Brahmawong C (2013) Development the Health Learning Center System for Provincial Hospitals in Thailand. J Health Med Informat 4: 127. doi:10.4172/2157-7420.1000127

Page 5 of 5

This study concerned itself with an examination of some existing HLC around the country. This initiative can serve as a system for all provincial hospitals. The significance of this study is based upon its value to individual staff and hospitals who are interested in health promotion and education. With today's knowledge about health promotion, it is essential that provincial hospitals be aware of the importance of learning environments for clients and people.

The HLC is conceptualized as a dynamic process. A key element of this system is the connection between main systems and sub-systems. The evaluation system is a key to continuously improving the quality and fidelity of the components within every system. The HLC involves a multitude of interrelated factors that are influenced by each other. This study confirms that the importance of coherent leadership at all levels, including the Provincial Public Health Office, is also essential to HLC accomplishments. Leadership, including the ability to be innovative, creates intra- and inter-organizational linkages, and enables hospitals and communities to engage in a change process.

The HLC in provincial hospitals encourages patients to acquire health information via various media. The patients can manipulate learning materials, explore best practices, discover and develop health promotion skills through self-study programs and a variety of activities arranged by hospital staff. Through HLC systems, all sections, wards, and departments of hospitals can create learning opportunities consciously and systematically.

The HLC system supports hospitals to better adapt to the changes of their learning environment. Its goal is to increase the hospitals health learning's effectiveness, not only in terms of health learning efficiency, but also in terms of quality of work and service. In health care it is one of the priorities for hospital to increase staff satisfaction and patient satisfaction with the health promotion service.

The success of HLC system depends on participation, commitment, and synergy among administrators, staffs, partnerships and local communities. The IT support from Division of Health Education, Department of Health Service Support, and Ministry of Public Health is required. The implementation of HLC system was successful and applicable to all provincial hospitals and it encourages many initiatives in small hospitals such as health knowledge database and health information management sub-systems.

The limited time frame of this study, as well as the difficulty in measuring the level of sustainability of the outcome, did not allow the researchers to measure the long-term impact of the intervention. Future research study needs to be undertaken to identify the learning outcomes and impact on health behavior for long-term sustainability. The study of important factors in each system and sub-system that influence on management process should be conducted in order to gain additional insight for management activity and participation among stakeholders.

\section{Acknowledgements}

The researcher would like to thank the Office of the Higher Education Commission, Thailand for supporting by granting fund under the program Strategic Scholarships for Frontier Research Network for the Thai doctoral degree program for this research and the research fund from the Division of Health Education Department of Health Service Support, Ministry of Public Health, Thailand.

\section{References}

1. (1986) Ottawa Charter for Health Promotion. First International Conference on Health Promotion (WHO) Ottawa.

2. (2006) The Guidelines for the development of a Health Education and Health Behavior Learning Center in Provincial Hospitals. Nontaburi: Department of Health Service Support, Thailand.

3. (2006) A Study of the Effect of Health Educational Process on Health Behavio Development. Department of Health Service Support Ministry of Public Health, Thailand.

4. Karam JA, Sundre SM, Smith GL (1986) A cost/benefit analysis of patient Education. Hosp Health Serv Adm 31: 82-90.

5. Richie ML (1994) Quality Management for Educational Technology Services. A Guide to Application of the Deming Management Method for District, University and Regional. Assn for Educational.

6. (2007) Educational Technology: ADefinition with Commentary. Alan Januszewsk \& Michael Molenda (Eds). Association for Educational Communications and Technology.

7. (2010) ISO’s Process Approach. Praxiom Research Group Limited. 